\title{
Resonance Two-Photon Ionization of Diarylethene in the Presence of Cyclodextrin
}

\author{
Michihiro Hara, Makoto Miwa, Tatsuya Takeshita, and Shouhei Watanabe \\ Department of Environmental and Biological Chemistry, Fukui University of Technology, 3-6-1 Gakuen, Fukui 910-8505, Japan \\ Correspondence should be addressed to Michihiro Hara; hara@fukui-ut.ac.jp
}

Received 21 May 2013; Accepted 1 August 2013

Academic Editor: Ugo Mazzucato

Copyright ( 2013 Michihiro Hara et al. This is an open access article distributed under the Creative Commons Attribution License, which permits unrestricted use, distribution, and reproduction in any medium, provided the original work is properly cited.

\begin{abstract}
The transient absorption of the diarylethene 1,2-bis(2,4-dimethyl-5-phenyl-3-thienyl)-3,3,4,4,5,5-hexafluoro-1-cyclopentene (DE) was measured using $266 \mathrm{~nm}$ laser flash photolysis in the presence of various cyclodextrins (CDs) in aqueous solvent. Ionization of DE occurred within the laser flash (5 ns) to give the DE radical cation and water-solvated electron. The electron was generated by two-photon excitation through simultaneous irradiation with $266 \mathrm{~nm}$ laser light, and the ionization quantum yields of DE in the presence of $\alpha-C D, \beta-C D, m-\beta-C D$, and $\gamma$-CD depended on the properties of the DE/CD complexes. These results suggest that useful two-photon ionization occurred for these complexes. The ionization quantum yield of DE was found to increase in aqueous solution after the addition of $\mathrm{m}-\beta-\mathrm{CD}(50 \mathrm{mM})$, in which $\mathrm{m}-\beta-\mathrm{CD}$ likely controlled the photochromic reactivity of DE.
\end{abstract}

\section{Introduction}

Research on the phenomenon of photochromism of organic compounds has advanced in recent years. Representative compounds with this property include azobenzene and spiropyrans $[1,2]$. The diarylethene, 1,2-bis(2,4-dimethyl5-phenyl-3-thienyl)-3,3,4,4,5,5-hexafluoro-1-cyclopentene, (DE) (Figure 1) used in our study also exhibits this property. Photochromism is a phenomenon where irradiation with certain wavelengths of light induces a reversible transformation between two structures without a change in molecular weight. Substances with this property are referred to as photochromic materials. Diarylethenes are superior to other photochromic materials in terms of thermal stability, high sensitivity, and durability with respect to repeated transformation. In addition, by introducing various substituents at the aryl position, the absorption spectrum can be changed to obtain different colors upon irradiation with ultraviolet light. These materials are expected to find uses in various applications, such as in memory devices in the IT field, as sensor materials for light modulation, or in the industrial field as well as in textile products (printed shirts). Due to the poor solubility of this DE in water, we used the inclusion effect of cyclodextrins (CDs) to dissolve it in water, after which we investigated its photoionization properties [2-16], which is a type of photolysis. The photochromic behavior of diarylethene derivatives attached to $\mathrm{CD}$ and dissolved in water has been reported to influence the quantum yield of the transformation from an open to a closed structure $[17,18]$. There are several varieties of $\mathrm{CD}$ depending on the number of glucose units, including the $\alpha$ ( 6 units), $\beta$ (7 units), and $\gamma$ (8 units) forms. A characteristic feature of CDs is their ability to form inclusion structures, whose vacant internal spaces display a hydrophobic nature, while the exterior is hydrophilic. Consequently, organic compounds in water can be dissolved by inserting them into the internal $C D$ vacant space.

While CD inclusion has been used to study the photochromic behavior of DE species in water, the effect of this inclusion on photoionization has not been reported. Because of their different cavity sizes, each of the CD species can accommodate a different portion of the DE molecule, which serves as a way to tune the local environment surrounding the DE. As more of the DE is included, its local environment becomes increasingly hydrophobic, which allows us to elucidate the effect of changing the environment on the ionization process.

In the present research, $\mathrm{DE}$ was dissolved in water using the inclusion effect of $\mathrm{CD}$, after which we examined its 

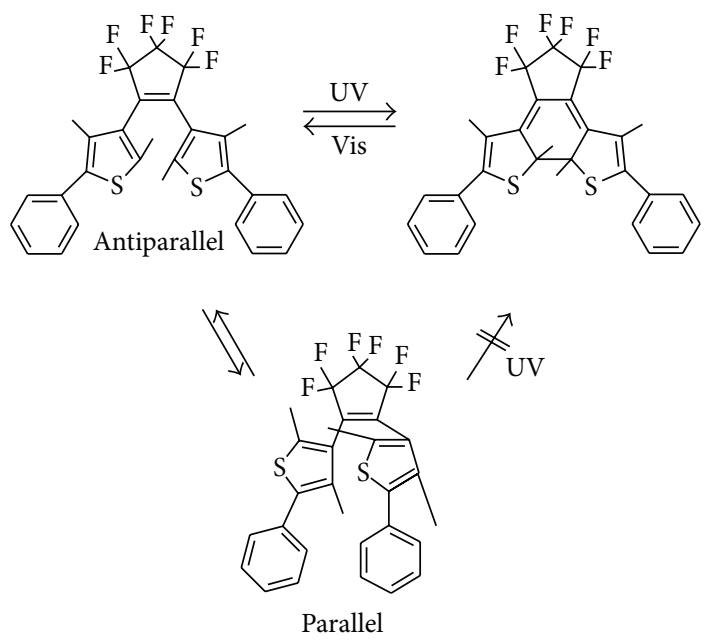

FIgURE 1: Reaction scheme of DE.

resonant two-photon ionization TPI [3] by laser flash photolysis (LFP), where the sample was irradiated with light at a wavelength of $266 \mathrm{~nm}$. From the observed $\Delta$ O.D. of the hydration electrons, we calculated the ionization quantum yield $\left(\Phi_{\text {ion }}\right)$ and examined the mechanism of TPI. We also conducted a comparative examination of the fluorescence lifetime $(\tau)$ since it is known to depend on $\Phi_{\text {ion }}$.

\section{Experimental}

We prepared aqueous solutions of the diarylethene 1,2bis(2,4-dimethyl-5-phenyl-3-thienyl)-3,3,4,4,5,5-hexafluoro1-cyclopentene (Tokyo Kasei) with various cyclodextrin varieties. Acetonitrile (spectroscopic grade) was purchased from Wako and benzophenone was purchased from Tokyo Kasei. $\alpha$-CD and $\beta$-CD were purchased from Nacalai Tesque, 6-O- $\alpha$-D-glucosyl- $\beta$-cyclodextrin $(\mathrm{m}-\beta$-CD) was obtained from Tokyo Kasei, and $\gamma$-CD was purchased from Kanto Chemical Co. Each of the DE/CD solutions were prepared in a 9:1 (v/v) water/acetonitrile (ACN) mixture. All the commercially available materials were used as received with no further purification. The DE concentration used for each study is indicated throughout the text, and the CD concentration was either 10 or $50 \mathrm{mM}$; because of its low solubility, we were not able to prepare a $50 \mathrm{mM} \beta$-CD solution. The DE solution and CD water solution were mixed simply, and the transparent samples were prepared.

The absorption and fluorescence spectra of the prepared samples were measured with a spectrophotometer (Hitachi, U-3310) and a fluorescence spectrophotometer (Perkin Elmer, LS55), respectively, and the fluorescence lifetime was measured with a fluorescence lifetime measurement device (Hamamatsu, C11369). The fluorescence lifetimes of DE were estimated with deconvolution analysis (Hamamatsu, U11487). In addition, single-wavelength irradiation was performed with a quadrupled YAG laser $(266 \mathrm{~nm}, 45 \mathrm{~mJ}, 5 \mathrm{~ns}$ pulse duration; Spectra-Physics GCR-130-10). Benzophenone was used as an actinometer for measuring the photon concentration. To observe the transient absorption ( $\Delta$ O.D.) of the hydration electrons, the wavelength for observation was set to $720 \mathrm{~nm}$. The obtained hydration electron density $\left(\left[\mathrm{e}_{\mathrm{aq}}^{-}\right]^{\prime}\right)$ was used to calculate $\Phi_{\text {ion }}$ as follow:

$$
\begin{aligned}
2 \Phi_{\text {ion }} & =\frac{\left[\mathrm{e}_{\mathrm{aq}}^{-}\right]^{\prime}}{[\text { photon }]} \\
& =\frac{\left(\Delta \mathrm{O}^{\mathrm{D}} \cdot{ }_{720} /\left(\varepsilon_{720} \times l\right)\right) / \mathrm{Abs}_{266}^{\mathrm{DE}}}{\left(\Delta \mathrm{O} \cdot \mathrm{D} \cdot{ }_{525} /\left(\varepsilon_{525} \times l\right)\right) / \mathrm{Abs}_{266}^{\mathrm{Bp}}} \\
& =\frac{\left[\mathrm{e}_{\mathrm{aq}}^{-}\right] / \mathrm{Abs}_{266}^{\mathrm{DE}}}{\left[{ }^{3} \mathrm{Bp}^{*}\right] / \mathrm{Abs}_{266}^{\mathrm{Bp}}} .
\end{aligned}
$$

Taking the triplet concentration $\left[{ }^{3} \mathrm{Bp}^{*}\right]$ of benzophenone (Bp) as the denominator and the concentration of hydration electrons $\left[\mathrm{e}_{\mathrm{aq}}^{-}\right]$as the numerator, $\Delta$ O.D. ${ }_{720}$ denotes $\Delta$ O.D. and $\varepsilon_{720}$ denotes $\varepsilon_{720}=1.85 \times 10^{4} \mathrm{M}^{-1} \mathrm{~cm}^{-1}$ for the hydration electrons. $\mathrm{Abs}_{266}^{\mathrm{DE}}$ is the absorbance at $266 \mathrm{~nm}$ of the solute sample when using LFP, $\Delta$ O.D. ${ }_{525}$ denotes $\Delta$ O.D. of Bp triplets, and $\varepsilon_{525}$ denotes $\varepsilon_{525}=6500 \mathrm{M}^{-1} \mathrm{~cm}^{-1}$ of Bp. Furthermore, $\mathrm{Abs}_{266}^{\mathrm{Bp}}$ denotes the absorbance of the Bp sample at $266 \mathrm{~nm}$ when LFP is used, and the factor 2 in $2 \Phi_{\text {ion }}$ accounts for the absorption of two photons.

The ionization potential (IP) of DE was calculated on the basis of cyclic voltammetry (CV) measurements with ACN as solvent and $\mathrm{DE}$ as the solute. We used $0.1 \mathrm{M}$ tetrabutylammonium as the electrolyte and an $\mathrm{Ag} / \mathrm{AgNO}_{3}$ reference electrode $(10 \mathrm{mM})$.

To estimate the extent of inclusion, each of the DE/CD complexes were modeled and subjected to geometry optimization to the most energetically stable structure using MM2 (CS Chem3D). Fully included CD structures were used as starting geometries. ${ }^{1} \mathrm{H}$ NMR spectra were measured on a $400 \mathrm{MHz}$ spectrometer (JEOL DATUM JNM-ATUM]) with the same concentrations used in the laser flash photolysis studies.

\section{Results and Discussion}

3.1. Structure of the DE/CD Complexes. The most stable, minimum-energy structures, formed through inclusion of $\mathrm{DE}$ into $\mathrm{CD}$, obtained from the results of MM2 calculations are shown in Figure 2, and these results were used to examine the structural differences between each of the CD complexes. The inner diameters of $\alpha-\mathrm{CD}, \beta-\mathrm{CD}, \mathrm{m}-\beta-\mathrm{CD}$, and $\gamma-\mathrm{CD}$ are $4.5,7.0,7.0$, and $8.5 \AA$, respectively, and the depth of the ring in all cases is $7.0 \AA$. The length of $\mathrm{DE}$ is $16.0 \AA$ along the long axis and $6.4 \AA$ along the short axis, and the length of the photoisomer of DE is $14.0 \AA$ along the long axis and $7.0 \AA$ along the short axis. The calculation results indicate that in the $\alpha$-CD inclusion complex only one of the DE benzene rings inserts into the $\mathrm{CD}$, while the hexafuluoro-cyclopentene group protrudes into the solution. The calculations indicate that the DE embeds deeper into the vacant space of $\beta-\mathrm{CD}$ and $\mathrm{m}-\beta$-CD than with $\alpha$-CD. Furthermore, $\gamma$-CD includes DE either fully (all the way into the center) or partially (including only the benzene rings of two DE molecules). With regard 


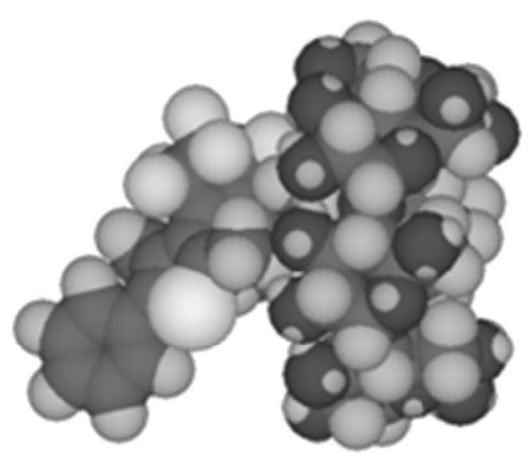

$\mathrm{DE} / \alpha-\mathrm{CD}$

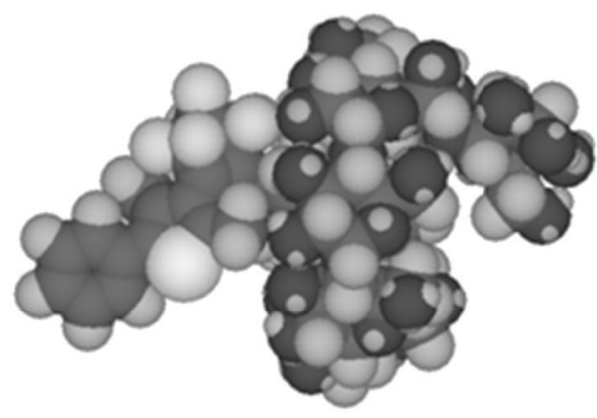

$\mathrm{DE} / \mathrm{m} \beta-\mathrm{CD}$

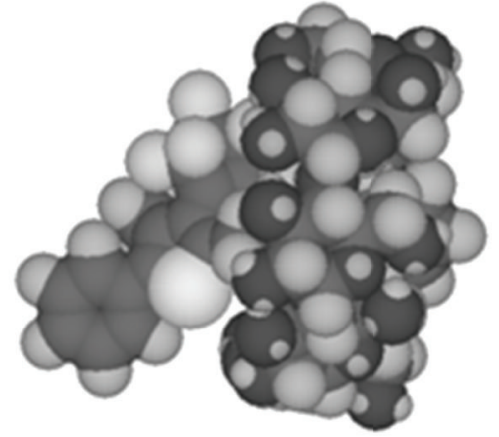

$\mathrm{DE} / \beta-\mathrm{CD}$

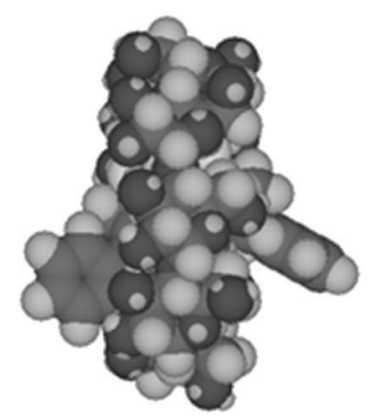

$\mathrm{DE} / \gamma-\mathrm{CD}$

Figure 2: Minimum-energy structures of DE/CD complexes calculated by MM2.

to the ionization process, when DE can be easily stabilized by solvent molecules, ionization is more efficient and the ionization quantum yield is likely to increase. Therefore, of all the complexes, the $\alpha$-CD complex should be the easiest to photoionize because a large portion of the DE protrudes into the solvent.

The open form structure of DE, which exhibits photoisomerism, exists in a parallel state and an antiparallel state $[17,18]$. The ${ }^{1} \mathrm{H}$ NMR spectrum of DE $\left(6.1 \times 10^{-3} \mathrm{M}\right.$, $20^{\circ} \mathrm{C}, 400 \mathrm{MHz}$ ) in deuterated ACN (no CD) showed peaks at $\delta 2.38$ and $2.40 \mathrm{ppm}$ which were assigned to the methyl protons at the 4 positions on the thiophene ring for the DE in the parallel and antiparallel conformations, respectively. The intensity ratio of the doublet peak indicates that the two DE conformations exist in almost equal populations in deuterated ACN. At our experimental solution concentrations, the methyl protons at the 2 positions on the DE thiophene ring expected around $\delta 2.0$ were not observed [19].

DE $\left(6.1 \times 10^{-3} \mathrm{M}, 20^{\circ} \mathrm{C}\right)$ was then suspended in the absence of $\mathrm{CD}$ in $\mathrm{H}_{2} \mathrm{O} / \mathrm{ACN}(9: 1)$. No significant $\mathrm{NMR}$ spectral peaks were observed for $\operatorname{DE}\left(6.1 \times 10^{-7} \mathrm{M}\right)$ at the LFP condition at around $2.4 \mathrm{ppm}$, which is the overlap signal of the methyl protons at the 4 positions on the thiophene ring for the $\mathrm{DE}$ and $\mathrm{H}_{2} \mathrm{O}(\delta$ 2.1) in deuterium $\mathrm{ACN}$. This is most likely because of the low DE concentration used in the experiments. Therefore, confirmation of the formation of the $\mathrm{DE} / \mathrm{CD}$ inclusion complexes was taken from shifts in the peak of the fluorescence spectra from $476 \mathrm{~nm}$ for DE solutions with no $\mathrm{CD}$ to $320-420 \mathrm{~nm}$ for DE/CD solutions (see Figure 3) as well as changes in the fluorescence lifetime profiles (see Figure 5, described later) [18].

3.2. Measurement of Absorption and Fluorescence Spectra and Fluorescence Lifetime. We measured the absorption and fluorescence spectra of aqueous solutions of DE $\left(6.1 \times 10^{-7} \mathrm{M}\right)$ in $\mathrm{H}_{2} \mathrm{O} / \mathrm{ACN}(9: 1)$ in the presence of CD, shown in Figure 3, for each of the CD species. As an example, we consider the results for the $\mathrm{DE} / \alpha-\mathrm{CD}$ inclusion complex. The maximum absorption was at $271 \mathrm{~nm}$ (Figure 3, black line), and the maximum fluorescence was at $421 \mathrm{~nm}$ (Figure 3, green line). Taking the wavelength at the maximum fluorescence, the singlet excitation energy $\left(S_{1}\right)$ was calculated to be $3.0 \mathrm{eV}$. Furthermore, cyclic voltammetry indicated a redox potential $E_{1 / 2}^{\mathrm{ox}}$ of $0.6 \mathrm{eV}$, and the ionization potential (IP) of DE in aqueous solution was calculated to be $6.7 \mathrm{eV}$, using the conversion formula [20]. Next, we measured the fluorescence lifetimes $(\tau)$ of the $\mathrm{CD} / \mathrm{DE}$ complexes in the 9:1 $\mathrm{H}_{2} \mathrm{O} / \mathrm{ACN}$ solutions. Representative spectra are shown in Figure 4, and a summary of the results for all systems is presented in Table 1. The measured $\tau$ consisted of three components $\tau_{1}, \tau_{2}$, and $\tau_{3}$, which were assumed to correspond to open ring parallel forms of DE only partially included within the CD (OP); closed ring, antiparallel forms of partially-included DE in CD (CL); and inclusion complexes, respectively. We note that the closed form could be generated by the excitation laser in the lifetime measurement; however, no solution color change was observed. Our assignment of the lifetime components is based on the reports of Irie et al. that the addition of CD to 
TABLE 1: Ionization quantum yields and fluorescence lifetimes of DE $\left(6.1 \times 10^{-5} \mathrm{M}\right)$ in the presence of $\alpha$-CD $\left(10^{-3}\right.$ or $\left.5 \times 10^{-3} \mathrm{M}\right), \beta-\mathrm{CD}$ $\left(10^{-3} \mathrm{M}\right), \mathrm{m}-\beta-\mathrm{CD}\left(10^{-3}\right.$ or $\left.5 \times 10^{-3} \mathrm{M}\right)$, or $\gamma$-CD $\left(10^{-3}\right.$ or $\left.5 \times 10^{-3} \mathrm{M}\right)$ in $\mathrm{H}_{2} \mathrm{O} / \mathrm{ACN}(9: 1)$.

\begin{tabular}{|c|c|c|c|c|c|c|c|c|c|}
\hline $\mathrm{CD}$ & $\mathrm{mM}$ & $\tau_{1}(\mathrm{~ns})$ & $\tau_{2}(\mathrm{~ns})$ & $\tau_{3}(\mathrm{~ns})$ & $A_{1}(\%)$ & $A_{2}(\%)$ & $A_{3}(\%)$ & $\mathrm{CHI}$ & $\Phi_{\text {ion }}(\%)$ \\
\hline$\alpha-\mathrm{CD}$ & 10 & 0.3 & 0.5 & 9.7 & 80 & 16 & 4 & 1.06 & 0.8 \\
\hline$\alpha-\mathrm{CD}$ & 50 & 0.4 & 2.8 & 16 & 67 & 26 & 7 & 1.03 & 0.6 \\
\hline$\beta-\mathrm{CD}$ & 10 & 0.7 & 3.7 & 32 & 72 & 26 & 2 & 1.00 & 0.8 \\
\hline $\mathrm{m} \beta-\mathrm{CD}$ & 10 & 0.5 & 3.7 & 19 & 90 & 9 & 1 & 1.04 & 0.6 \\
\hline $\mathrm{m} \beta-\mathrm{CD}$ & 50 & 1.0 & 3.7 & 20 & 51 & 44 & 5 & 1.01 & 1.1 \\
\hline$\gamma-\mathrm{CD}$ & 10 & 0.7 & 4.4 & 33 & 91 & 8 & 1 & 1.01 & 0.9 \\
\hline$\gamma-\mathrm{CD}$ & 50 & 0.8 & 3.8 & 28 & 89 & 10 & 1 & 1.02 & 0.7 \\
\hline
\end{tabular}

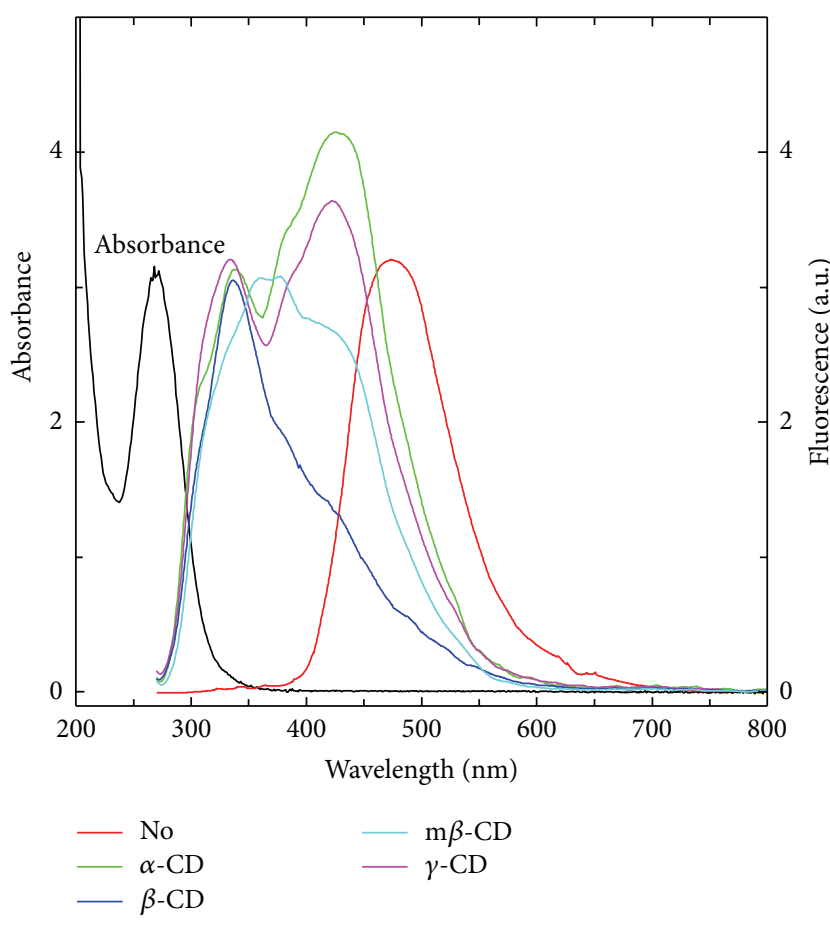

FIGURE 3: Absorption (black line) and fluorescence spectra of DE in the absence (red line, no CD, pure ACN solvent) and presence of $\alpha$ $\mathrm{CD}$ (green), $\beta$-CD (blue), $\mathrm{m}-\beta$-CD (cyan), and $\gamma$-CD (magenta). All $\mathrm{CD}$ solutions were $[10 \mathrm{mM}]$ in $\mathrm{H}_{2} \mathrm{O} / \mathrm{ACN}(9: 1)$.

an aqueous solution of the open-ring form DE increased the abundance of the antiparallel conformation $[17,18]$. With the addition of CD (from 10 to $50 \mathrm{mM}$ ), the fluorescence lifetimes of DE were affected (see Table 1). The $A_{2}$ factor increased and the $A_{1}$ factor decreased when increasing the CD concentration. Hence, the $A_{1}$ and $A_{2}$ factors should be derived from the parallel and antiparallel conformations. Because it is 100-fold longer than the single-component fluorescence lifetime of pure DE in organic solvent [21], we have assigned is the $\tau_{3}$ component to the inclusion complex.

Here, $\Phi_{\text {ion }}$ is considered to depend on the existence probability of the second photon, and the fluorescence lifetime is one of the important physical measures in this respect. Looking at the values of the fluorescence lifetime of DE, longer fluorescence lifetimes are considered to be associated with ionization. Comparing $\tau_{1}, \tau_{2}$, and $\tau_{3}$ of DE in the presence of

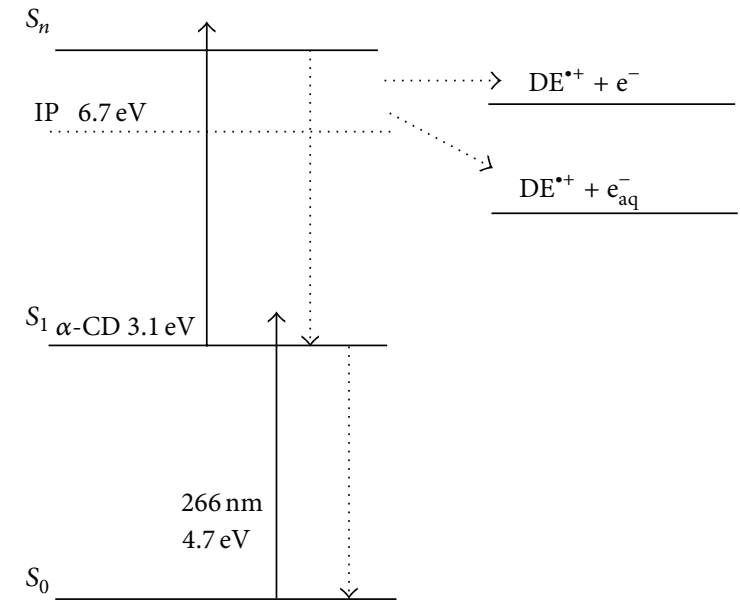

FIGURE 4: Energy-level diagram for DE in the ground state and excited state.

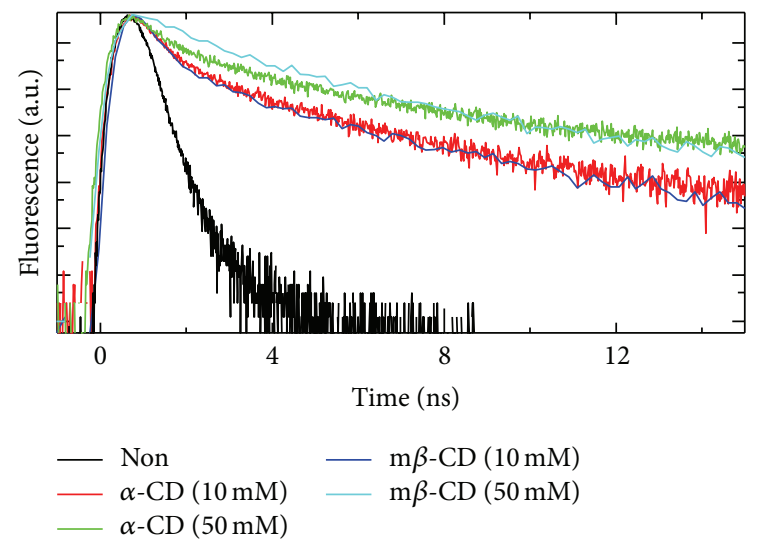

FIgURE 5: Representative time profiles of fluorescence lifetimes of $\mathrm{DE}$ in the absence (black line) and the presence of $\alpha$-CD $(10 \mathrm{mM}$, red line; $50 \mathrm{mM}$, green line), or $\mathrm{m} \beta$-CD $(10 \mathrm{mM}$, blue line; $50 \mathrm{mM}$, cyan line) in ACN or $\mathrm{H}_{2} \mathrm{O} / \mathrm{ACN}(9: 1)$, respectively.

each $\mathrm{CD}, \tau_{1}$ was longer (1.0 ns) and the ionization quantum yield was higher when $50 \mathrm{mM}$ of $\mathrm{m}-\beta$-CD was added.

3.3. Two-Photon Ionization of DE. Hydration electrons $(720 \mathrm{~nm})$ were observed upon irradiation with $266 \mathrm{~nm}$ (45 mJ) laser light of the $(9: 1) \mathrm{H}_{2} \mathrm{O} / \mathrm{ACN}$ DE/CD complex 


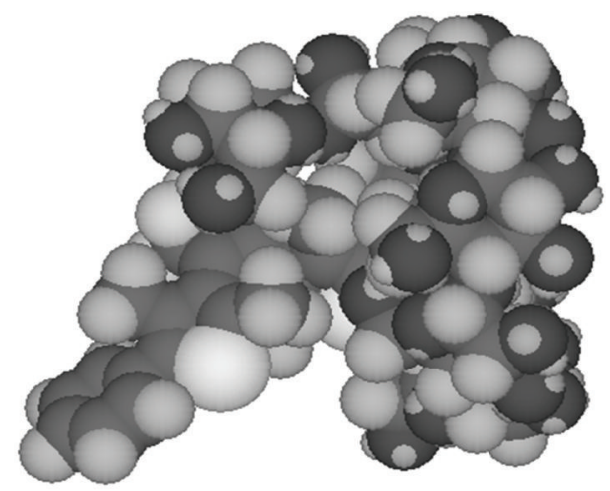

FIgURE 6: Minimum-energy structure of the DE/m- $\beta$-CD complex calculated by MM2.

solutions, which indicates ionization of the DE molecule. Since ionization to IP $(6.7 \mathrm{eV})$ is impossible to achieve with the energy of a single photon $(266 \mathrm{~nm}, 4.7 \mathrm{eV})$, it was implied that ionization is induced by two or more photons (Figure 5).

The values of $\Phi_{\text {ion }}$ for the various $\mathrm{DE} / \mathrm{CD}$ complex solutions are shown in Table 1 . The $\Phi_{\text {ion }}$ value for $\alpha$-CD $(10 \mathrm{mM})$ and $\beta-\mathrm{CD}(10 \mathrm{mM})$ was the same $(0.8 \%)$. However, the fluorescence lifetime values of $\tau_{1}, \tau_{2}$, and $\tau_{3}$ were longer for $\beta$-CD, changing from $0.3 \mathrm{~ns}$ to $0.7 \mathrm{~ns}$, from $0.7 \mathrm{~ns}$ to $3.7 \mathrm{~ns}$, and from $9.7 \mathrm{~ns}$ to $32 \mathrm{~ns}$, respectively. In the same manner, a comparison for $\mathrm{m}-\beta-\mathrm{CD}$ and $\gamma-\mathrm{CD}$ at $10 \mathrm{mM}$ revealed no dependence on the fluorescence lifetime.

Regarding the concentration effect of each $\mathrm{CD}$ variety, $\Phi_{\text {ion }}$ for $\alpha$-CD and $\gamma$-CD decreased by about $20 \%$ as the concentration increased. This is considered to be due to the increased difficulty of receiving the solvation stabilization energy.

However, in the case of $\mathrm{m}-\beta-\mathrm{CD}$, in addition to $\tau_{1}$ becoming longer (from $0.5 \mathrm{~ns}$ to $1.0 \mathrm{~ns}$ ), $\Phi_{\text {inn }}$ also increased from $0.6 \%$ to $1.1 \%$. This increase is partially because the amount of $\mathrm{DE}$ inclusion in $\mathrm{CD}$ increases at high concentrations, but also because when the $\mathrm{DE}$ is included on the maltose side (Figure 6), or if the DE and CD form a 1:2 complex, DE isomerization immediately after irradiation is blocked. This suppresses the photochromic reaction transforming the open form to closed form, and, as a result, the average lifetime becomes longer and TPI occurs more readily.

\section{Conclusion}

In the present research, we used aqueous solutions of $\mathrm{DE}$ in $\mathrm{H}_{2} \mathrm{O} / \mathrm{ACN}(9: 1)$ in the presence of $\alpha-\mathrm{CD}, \beta-\mathrm{CD}, \mathrm{m}-\beta-\mathrm{CD}$, and $\gamma$-CD and calculated the respective values of $\Phi_{\text {ion }}$ upon irradiation with laser light with a wavelength of $266 \mathrm{~nm}$. Subsequently, we conducted a comparative examination of TPI observations and the CD concentration effect. In addition, since it is known that the fluorescence lifetime $(\tau)$ depends on $\Phi_{\text {ion }}$, we conducted a comparative investigation of this relation as well. In this regard, TPI of DE was observed upon irradiation with $266 \mathrm{~nm}$ light in the presence of all varieties of CD. Among them, the TPI of DE in the presence of $\mathrm{m}$ $\beta$-CD suppressed the photochromic reaction by increasing the concentration of $\mathrm{CD}$, resulting in a longer $\tau_{1}$ and an increased value of $\Phi_{\text {ion }}$. Consequently, we determined that the addition of $50 \mathrm{mM} \mathrm{m}-\beta-\mathrm{CD}$ is useful with regard to $\Phi_{\text {ion }}$ in the presence of CD as well as that the photochromic reaction is affected by the concentration effect of $\mathrm{CD}$, which results in differences in the values of $\Phi_{\text {ion }}$.

\section{Conflict of Interests}

The authors report no conflict of interests.

\section{Acknowledgment}

This research was supported by the MEXT* ${ }^{*}$-Supported Program for the Strategic Research Foundation at Private Universities, 2011-2016 ( ${ }^{*}$ Ministry of Education, culture, Sports, Science and Technology).

\section{References}

[1] M. Irene, "Diarylethenes for memories and switches," Chemical Reviews, vol. 100, no. 5, pp. 1685-1716, 2000.

[2] R. A. McClelland, N. Mathivanan, and S. Steenken, "Laser flash photolysis of 9-fluorenol. Production and reactivities of the 9fluorenol radical cation and the 9-fluorenyl cation," Journal of the American Chemical Society, vol. 112, no. 12, pp. 4857-4861, 1990.

[3] J. N. Greeley, J. S. Martin, J. R. Morris, and D. C. Jacobs, "Scattering aligned $\mathrm{NO}^{+}$on $\mathrm{Ag}(111)$ : the effect of internuclear-axis direction on $\mathrm{NO}^{-}$and $\mathrm{O}^{-}$product formation," The Journal of Chemical Physics, vol. 102, no. 12, pp. 4996-5011, 1995.

[4] R. Weinkauf, P. Schanen, A. Metsala, E. W. Schlag, M. Bürgle, and H. Kessler, "Highly efficient charge transfer in peptide cations in the gas phase: threshold effects and mechanism," Journal of Physical Chemistry, vol. 100, no. 47, pp. 18567-18585, 1996.

[5] M. Hara, S. Tojo, and T. Majima, "Three-color three-laser photochemistry of $\operatorname{di}(p$-methoxyphenyl)methyl chloride," Journal of Physical Chemistry A, vol. 107, no. 24, pp. 4778-4783, 2003.

[6] R. Weinkauf, L. Lehr, and A. Metsala, "Local ionization in 2phenylethyl-N,N-dimethylamine: charge transfer and dissociation directly after ionization," Journal of Physical Chemistry A, vol. 107, no. 16, pp. 2787-2799, 2003.

[7] M. Hara, S. Tojo, M. Fujitsuka, and T. Majima, "Relationship between formation yield of radical cation and laser intensity during resonant two-photon ionization of stilbene and methoxyl-substituted stilbenes using a 25-ns XeCl excimer laser," Chemical Physics Letters, vol. 393, pp. 338-342, 2004.

[8] M. Hara, S. Tojo, K. Kawai, and T. Majima, "Formation and decay of pyrene radical cation and pyrene dimer radical cation in the absence and presence of cyclodextrins during resonant two-photon ionization of pyrene and sodium 1-pyrene sulfonate," Physical Chemistry Chemical Physics, vol. 6, no. 13, pp. 3215-3220, 2004.

[9] M. Hara, S. Tojo, and T. J. Majima, "Formation efficiency of radical cations of stilbene and methoxy-substituted stilbenes during resonant two-photon ionization with a $\mathrm{XeCl}$ excimer laser," Journal of Photochemistry and Photobiology A, vol. 162, pp. 121-128, 2004.

[10] S. Wiedemann, A. Metsala, D. Nolting, and R. Weinkauf, "The dipeptide cyclic(glycyltryptophanyl) in the gas phase: a concerted action of density functional calculations, S0-S1 
two-photon ionization, spectral UV/UV hole burning and laser photoelectron spectroscopy," Physical Chemistry Chemical Physics, vol. 6, no. 10, pp. 2641-2649, 2004.

[11] M. Hara, S. Samori, X. Cai, M. Fujitsuka, and T. Majima, "Importance of properties of the lowest and higher singlet excited states on the resonant two-photon ionization of stilbene and substituted stilbenes using two-color two-lasers," Journal of Physical Chemistry A, vol. 109, no. 43, pp. 9831-9835, 2005.

[12] M. Hara, S. Samori, C. Xichen, M. Fujitsuka, and T. Majima, "Effect of oxygen on the formation and decay of stilbene radical cation during the resonant two-photon ionization," Journal of Organic Chemistry, vol. 70, no. 11, pp. 4370-4374, 2005.

[13] L. Lehr, T. Horneff, R. Weinkauf, and E. W. Schlag, "Femtosecond dynamics after ionization: 2-phenylethyl-N,N-dimethylamine as a model system for nonresonant downhill charge transfer in peptides," Journal of Physical Chemistry A, vol. 109, no. 36, pp. 8074-8080, 2005.

[14] R. Brause, H. Fricke, M. Gerhards, R. Weinkauf, and K. Kleinermanns, "Double resonance spectroscopy of different conformers of the neurotransmitter amphetamine and its clusters with water," Chemical Physics, vol. 327, no. 1, pp. 43-53, 2006.

[15] F. Remacle, R. Weinkauf, and R. D. Levine, "Molecule-based photonically switched half and full adder," Journal of Physical Chemistry A, vol. 110, no. 1, pp. 177-184, 2006.

[16] S. Samori, M. Hara, S. Tojo, M. Fujitsuka, and T. Majima, "Important factors for the formation of radical cation of stilbene and substituted stilbenes during resonant two-photon ionization with a 266- or 355-nm laser," Journal of Photochemistry and Photobiology A, vol. 179, no. 1-2, pp. 115-124, 2006.

[17] M. Takeshita and M. Irie, "Enhancement of the photocyclization quantum yield of $2,2^{\prime}$-dimethyl-3,3' -(perfluorocyclopentene1,2-diyl)bis(benzo[b]-thiophene-6-sulfonate) by inclusion in a cyclodextrin cavity," Chemical Communications, no. 23, pp. 2265-2266, 1997.

[18] M. Takeshita, N. Kato, S. Kawauchi, T. Imase, J. Watanabe, and M. Irie, "Photochromism of dithienylethenes included in cyclodextrins," Journal of Organic Chemistry, vol. 63, no. 25, pp. 9306-9313, 1998.

[19] M. Irie, K. Sakemura, M. Okinaka, and K. Uchida, "Photochromism of dithienylethenes with electron-donating substituents," Journal of Organic Chemistry, vol. 60, no. 25, pp. 8305-8309, 1995.

[20] F. Wilkinson and C. Tsiamis, "Quenching of triplet states of organic compounds by chromium(III) tris(hexafluoroacetylacetonate) in benzene solution as a result of energy and electron transfer," Journal of the American Chemical Society, vol. 105, no. 4, pp. 767-774, 1983.

[21] H. Miyasaka, T. Nobuto, M. Murakami, A. Itaya, N. Tamai, and M. Irie, "Solvent viscosity effects on photochromic reactions of a diarylethene derivative as revealed by picosecond laser spectroscopy," Journal of Physical Chemistry A, vol. 106, no. 35, pp. 8096-8102, 2002. 

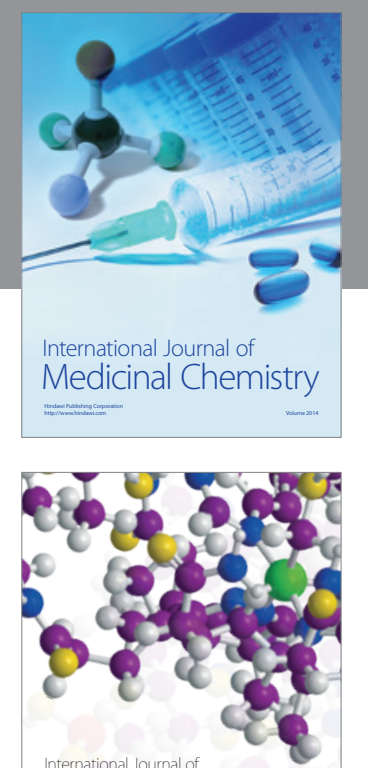

\section{Carbohydrate} Chemistry

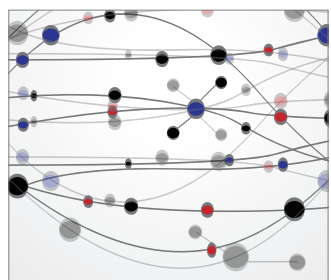

The Scientific World Journal
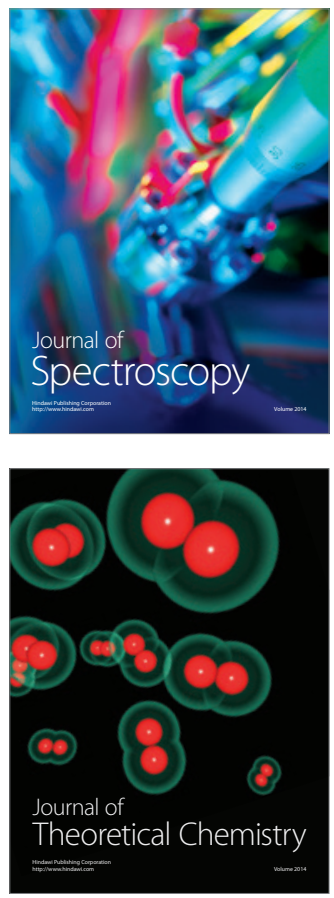
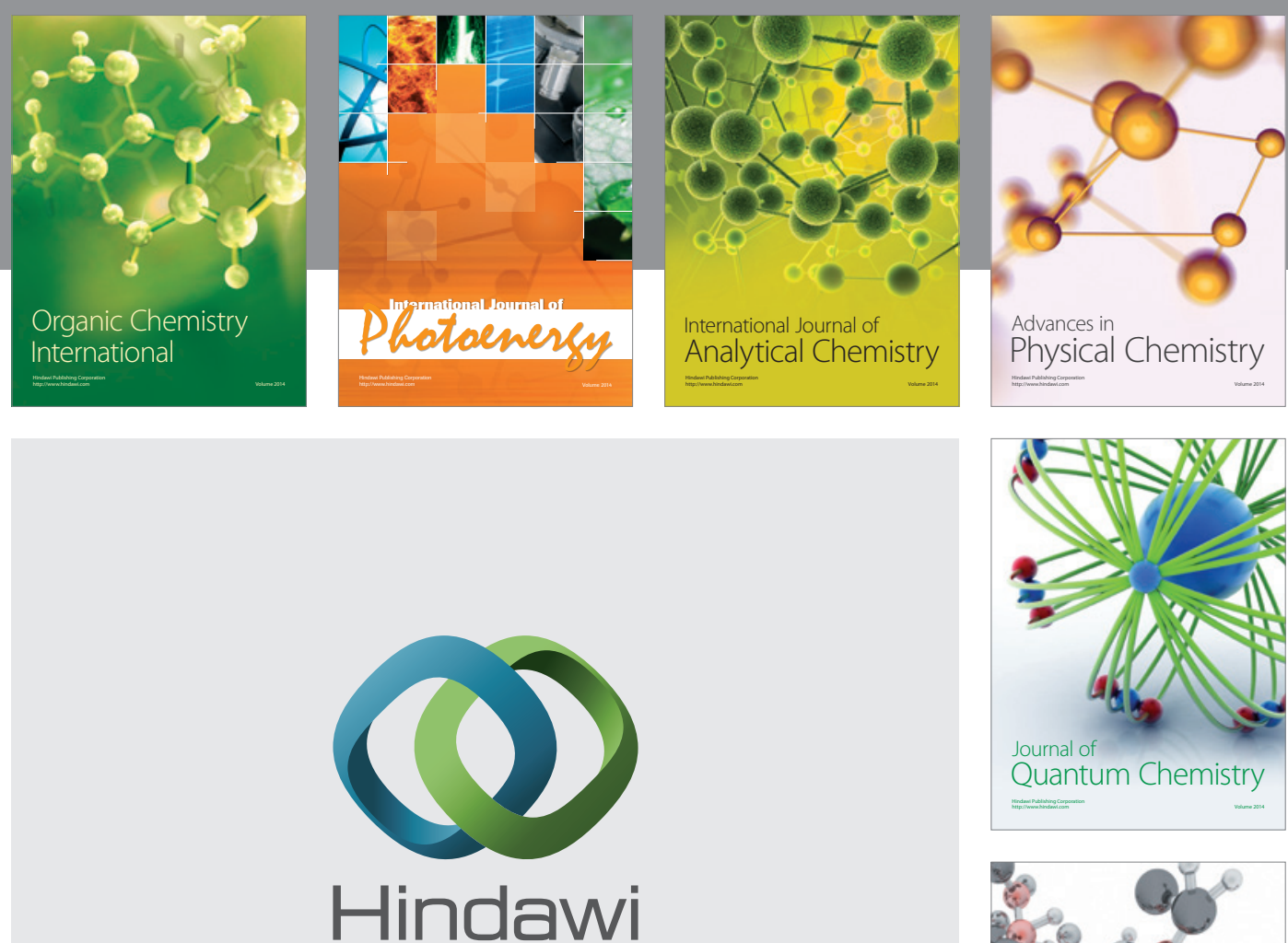

Submit your manuscripts at

http://www.hindawi.com

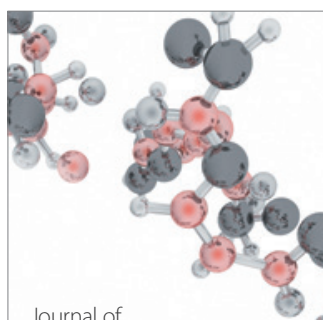

Analytical Methods

in Chemistry

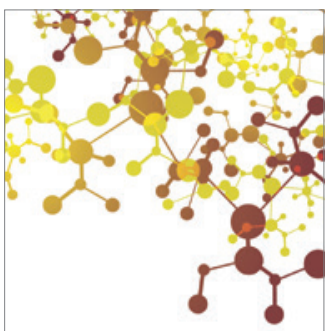

Journal of

Applied Chemistry

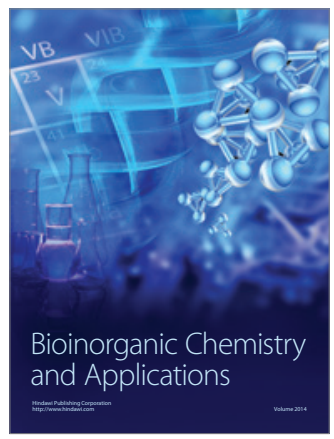

Inorganic Chemistry
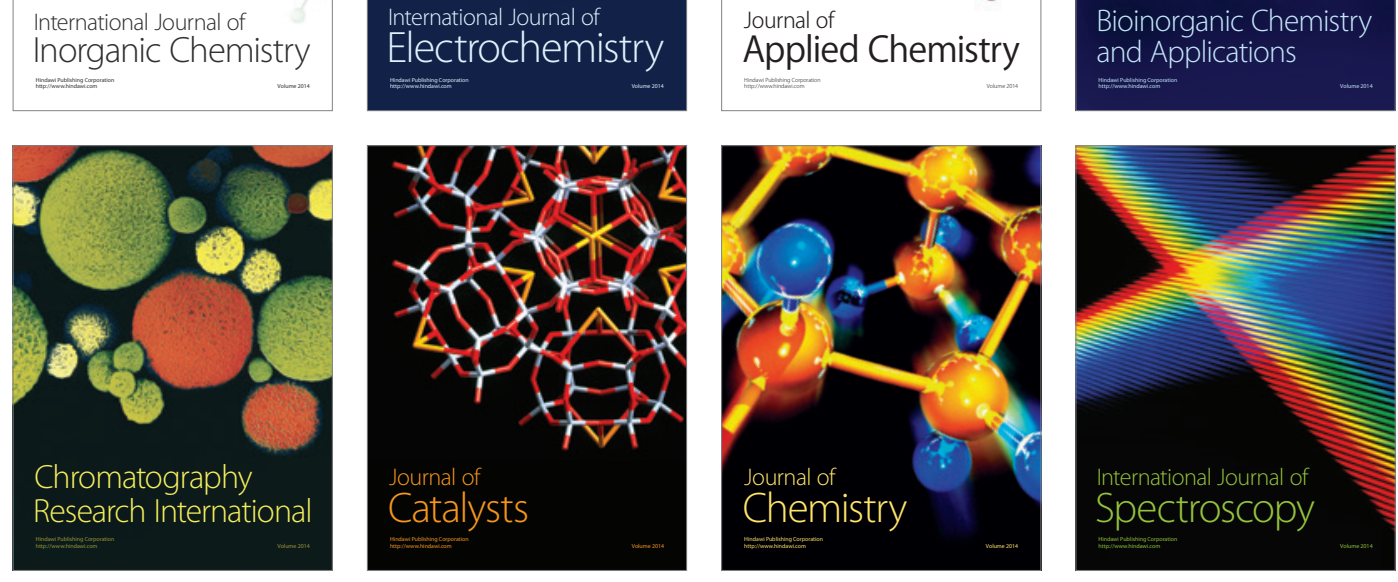